University of Zurich

Department of Economics

Working Paper Series

ISSN 1664-7041 (print)

ISSN 1664-705X (online)

Working Paper No. 247

\title{
Inside Money, Investment, and Unconventional Monetary Policy
}

\author{
Lukas Altermatt
}

Revised version, July 2019 


\title{
Inside Money, Investment, and Unconventional Monetary Policy*
}

\author{
Lukas Altermatt ${ }^{\dagger}$
}

July 10, 2019

\begin{abstract}
I develop a model that explicitly takes the role of financial institutions in the transmission mechanism of monetary policy into account. Within this model, I find various equilibrium environments, with one of them resembling a standard environment for monetary policy and another one akin to a liquidity trap. I analyze what the effects of various monetary policy measures such as quantitative easing, open-market operations, helicopter money and negative interest rates are in all of these environments. I find that open-market operations, quantitative easing, and negative interest rates on reserves are powerless in a liquidity trap, while helicopter money can be used to increase investment. The model also shows that a floor system allows a central bank to implement monetary policy with less side effects, but at the cost of losing control over inflation through open-market operations.
\end{abstract}

Keywords: New monetarism, liquidity trap, helicopter money, negative interest rates, government debt, Ricardian equivalence, banking, floor vs. channel system

JEL codes: E43, E52, E63, G21, H63

*I am grateful to my adviser Aleksander Berentsen for his useful comments that greatly improved the paper and to my colleagues Mohammed Ait Lahcen, Florian Madison, and Romina Ruprecht for many insightful discussions. I thank Cyril Monnet, Randall Wright, David Andolfatto, Chris Waller, Francesca Carapella, Lucas Herrenbrueck, Thanasis Geromichalos, Florin Bilbiie, Kenza Benhima, Gabriele Camera, Dirk Niepelt, and seminar participants at the Universities of Basel and Wisconsin-Madison, and various conferences. I acknowledge support from the FAG Basel for this project.

${ }^{\dagger}$ University of Wisconsin-Madison and University of Basel. lu.altermatt@gmail.com 


\section{Introduction}

After the financial crisis of 2007-2009, the conditions faced by monetary policy have changed. Interest rates on bank deposits, bonds, and policy rates have been severely lowered in many developed economies. But even with such record-low rates, policymakers were worried about the output gap and a lack of investment. Simultaneously, central banks have also consistently undershot their inflation targets. In order to reduce the output gap and increase investment, some central banks have tried untested policies such as quantitative easing, forward guidance, interest rates on reserves

- both negative and positive, and have considered implementing other policies, such as helicopter money.

The most obvious reason for the issues monetary policy faced after the financial crisis is the zero lower bound. At the zero lower bound, a further (substantial) decrease in the nominal interest rate is infeasible due to the existence of cash. The scenario where the interest rate becomes stuck at the zero lower bound is usually referred to as a liquidity trap. The experiences after the financial crisis demonstrated that many monetary policy tools don't work as intended in a liquidity trap. The question therefore arises which policy tools can be used in a liquidity trap to affect economic variables such as inflation, output, consumption, investment, and welfare.

More generally, these observations suggest that there are multiple environments for monetary policy, but the literature so far focused mainly on a standard environment, where monetary policy tools work as intended. The goal of this paper is therefore twofold: First, I want to build a model that allows for multiple environments which can occur endogenously, and second, I want to analyze how different monetary policy tools affect economic variables in each of these environments. Within this analysis, I will put a special focus on the environment that resembles a liquidity trap, in order to understand why liquidity traps can arise, and which monetary policy tools are useful in a liquidity trap. The monetary policy tools I am studying in this paper are open-market operations, quantitative easing, and helicopter money. I also analyze how the environment for monetary policy changes when the central bank starts paying interest on reserves, and what the advantages and disadvantages of a floor system are compared to a channel system.

To achieve the goals of this paper, I extend the model of Lagos and Wright (2005) to make the role of the financial sector in the transmission of monetary policy explicit. Specifically, I distinguish between the monetary base M0 issued by the central bank, and the monetary aggregate M1, which consists of cash and inside money issued by banks. To issue inside money, banks can either lend to entrepreneurs, hold government bonds, or hold reserves. To create inside money and 
make investments, banks need deposits ${ }^{1}$. Agents are willing to make these deposits because they need liquid assets to trade, and inside money weakly dominates cash due to interest rate payments. Deposit market clearing determines the amount of inside money issued and the deposit interest rate. Banks are essential in the model because they perform liquidity transformation: They are able to extend the set of liquid assets by investing in illiquid assets like government bonds and capital (lending to entrepreneurs). On the one hand, this makes it easier for agents to acquire consumption, because the interest rate on deposits reduces the cost of holding liquid assets. On the other hand, this allows entrepreneurs to invest more and the government to get a cheaper source of refinancing, because the interest rate they have to pay the bank is lower due to the liquidity premium on deposits ${ }^{2}$. This also creates a trade-off between liquid asset holdings and investment: A lower deposit interest rate simultaneously lowers liquid asset holdings and increases investment. If there are no commitment issues between banks and entrepreneurs, the Fisher interest rate as defined by Geromichalos and Herrenbrueck (2017) - the interest rate which exactly compensates for inflation and discounting - delivers first-best investment and liquid asset holdings. With limited commitment of entrepreneurs, it is impossible to simultaneously reach first-best in both dimensions, such that there is a real policy trade-off. In this case, lowering the real interest rate increases investment, but lowers consumption financed by liquid assets, while an increase in the real interest rate does the opposite. Various model parameters determine whether an increase or a decrease in the real interest rate is increasing overall welfare. Therefore, the question for monetary policy is how it can affect the real interest rate in different equilibrium environments.

Importantly, the goal of this paper is not to explain why the financial crisis happened, but rather to offer different reasons why conditions for monetary policy could change, and then identify the effects of different monetary policy tools given these new circumstances. For example, an economy can end up in a liquidity trap both due to real shocks, which would be captured by changes in the return on capital, or due to commitment issues, as captured by changes in the ability of entrepreneurs to repay loans. In the former case, the right policy reaction is to increase real interest rates and reduce lending, while in the latter case, the right policy reaction is to lower real interest rates and increase lending. Thus, this paper should be seen as a manual about how

\footnotetext{
${ }^{1}$ This is true even though banks can create money to make loans. In equilibrium, someone has to be willing to hold liquid assets - if banks create more inside money than the market wants to hold, prices adjust, thereby reducing the real value of the inside money created.

${ }^{2}$ This generalizes a result from Lagos and Rocheteau (2008). Lagos and Rocheteau show that liquid capital pays a liquidity premium if liquidity is scarce. Here, the same is true even though capital and bonds themselves are not liquid: the banks' ability to issue a liquid asset by investing in illiquid assets assigns the liquidity premium also to these illiquid assets.
} 
different policies affect the economy in different circumstances. The paper is not about how to identify the circumstances the economy finds itself in, but rather about how to react optimally given the observed circumstances.

There are four equilibrium environments for monetary policy in the model, with one of them most closely resembling a conventional environment regarding the effects of monetary policy, and another representing the liquidity trap environment. The equilibrium environments can be identified by the banks' investment decisions and the interest rate on deposits. There are several factors that influence in which environment an economy ends up: The return on investment, the demand for liquid assets, the severity of limited commitment issues, but also policy variables such as the inflation rate and the bonds-to-money ratio.

An important novelty in this paper is that I strictly distinguish between newly created currency issued through purchases of government bonds or through lump-sum taxes. I define the former as an open-market operation and the latter as helicopter money. This distinction matters, because an open-market operation simultaneously changes the bonds-to-money ratio and the amount of currency in circulation, while helicopter money does not directly affect the bonds-to-money ratio. Another policy tool I analyze is quantitative easing, which I interpret as a one-time, large purchase of government bonds ${ }^{3}$. This policy affects the bonds-to-money ratio, and therefore allows the monetary authority to transition from one equilibrium environment to another.

The conventional environment (later labeled as equilibrium case 3) exists for deposit interest rates strictly between zero and the Fisher interest rate. In the conventional environment, an increase in the fiat money growth rate induced by an open-market operation leads to an increase in inflation, a decrease in interest rates, and an increase in investment. The liquidity trap environment (later labeled as equilibrium case 4) exists at the zero lower bound, or if the central bank implements a floor system. In this environment, banks hold excess reserves. An open-market operation cannot affect inflation or investment in a liquidity trap, because reserves and government bonds are perfect substitutes from the banks' point of view, making a swap of them irrelevant. Instead, the central bank can use helicopter money. This policy can increase inflation even in a liquidity trap, which leads to an increase in investment, and to an increase in welfare if limited commitment issues between banks and entrepreneurs are substantial.

Quantitative easing can be used to increase investment in the conventional environment, but not

\footnotetext{
${ }^{3}$ There are similarities between open-market operations and quantitative easing, both in reality and in my model. Here, an open-market operation is a policy tool which is continuously employed, while quantitative easing is a onetime event.
} 
in a liquidity trap. Quantitative tightening can be used to increase interest rates and thereby lower investment. If limited commitment issues are small, this increases welfare.

Starting in a liquidity trap environment, the monetary authority can increase the deposit interest rate by paying interest rates on reserves. An alternative way to do so is to reduce the amount of outstanding reserves by implementing quantitative tightening. These two methods can be interpreted as a floor and a channel system, respectively. In a channel system, the monetary authority has to control the interest rate on deposits through open-market operations, which also affect the inflation rate. In a floor system, changing the interest rate on reserves directly changes the deposit interest rate, leaving the inflation rate unchanged. However, since open-market operations are powerless when banks hold reserves, the only way for the monetary authority to affect the inflation rate in a floor system is to implement helicopter money.

Introducing negative interest rates on reserves in a liquidity trap environment reduces the amount of deposits in the economy, but this decrease is offset by an increase in cash holdings by agents, thus rendering the policy ineffective.

Existing literature. As explained above, the financial crisis of 2007-2009 has posed many challenges to monetary policy and has induced researchers to think hard about the role of money and the capabilities of monetary policy tools. A natural framework to study these issues is the New Monetarism literature based on Kiyotaki and Wright (1989) and Lagos and Wright (2005). Some articles from the New Monetarism literature on the financial crisis, the liquidity trap, and openmarket operations are Williamson (2012, 2016), Andolfatto and Williamson (2015), Geromichalos and Herrenbrueck (2017), Herrenbrueck (2019), Dai and He (2018), Boel and Waller (2019) or Rocheteau et al. (2018). Among those, this paper shares most similarities with Williamson (2012), as both focus on the role of the financial system for monetary policy transmission. However, the model in this paper differs from Williamson for four main reasons: (1) the role of banks is different, as they perform liquidity transformation in my model, while they perform insurance against liquidity shocks in Williamson (2012); (2) I differentiate between open-market operations and helicopter money; (3) I can study the effect of various monetary policy tools on investment; and (4) for some parameters, increasing inflation is beneficial because it increases investment. These differences allow me to find the new results mentioned above.

In the general literature on monetary economics, two of the earliest papers that study monetary policy in a liquidity trap are Krugman et al. (1998) and Eggertsson and Woodford (2003, 2004). 
Krugman et al. study the issue of a liquidity trap in the context of Japan's experience in the 1990s in a variety of simple models, and find that an expansion of the monetary base has no effect on broader monetary aggregates due to credibility problems. Similarly, Eggertsson and Woodford argue that an open-market operation at the zero lower bound is ineffective only if it does not alter expectations about future inflation. Werning (2012) also focuses on the role of expectations at the zero lower bound. After the financial crisis, there was a surge in articles about the liquidity trap and monetary policy at the zero lower bound. There seems to be general agreement that more government debt is beneficial in such situations; however the reasons for this being so differ. While New Keynesian papers emphasize the role of government spending (e.g., Eggertsson and Krugman (2012) or Christiano et al. (2011)) or tax policy (e.g., Correia et al. (2013)), the papers from the New Monetarism literature mentioned above show that government debt is important, since at the zero lower bound there is a shortage of liquid assets in the economy, which an increase in government bonds could help to overcome. In my paper, a lack of government debt is also one possible cause of a liquidity trap.

Bacchetta et al. (2016) show that quantitative easing in a liquidity trap only worsens the problem, and that negative interest rates may help an economy to get out of a liquidity trap, but are unable to solve the underlying problem, which is asset scarcity. Guerrieri and Lorenzoni (2017) study the liquidity trap in a model with heterogeneous agents and incomplete markets. They calibrate output responses in a liquidity trap after adverse shocks to borrowing capacities, and find that drops in output are more severe in a liquidity trap. Cochrane (2017) offers an alternative view on a liquidity trap in a new-Keynesian framework, namely that there is also an equilibrium at the zero lower bound which predicts small effects on inflation, output, and policy.

Research about helicopter money and negative interest rates is still at an early stage. Kiyotaki and Moore (2012) study the effect of open market operations and helicopter money after a liquidity shock. Contrary to my paper's results, they find that open market operations have real effects, while helicopter money does not. Their contrary findings stem from the fact that there is no role for assets as investment opportunities for banks in their paper. Buiter (2014) argues that if three conditions are satisfied (i.e., fiat money is held for other reasons than its return, fiat money is irredeemable, and the price of money is positive), helicopter money can always be used to boost demand, which in turn increases inflation. All of these conditions are satisfied in my model, so my results support Buiter's claim. On the other hand, Gali (2014) shows that a money-financed fiscal stimulus (i.e., something like helicopter money) has strong effects on economic activity, but only relatively mild inflationary consequences. However, the way helicopter money affects the economy 
is quite different in both Buiter's and Gali's work compared to my paper.

The research on negative interest rates has been developing mainly in Europe, as only European countries have implemented negative policy rates so far. Demiralp et al. (2017) empirically study the effects of the introduction of negative rates in the Eurozone on banks' activities and find that the reaction is different from standard rate cuts in positive-rate territory. In a theoretical paper, Dong and Wen (2017) show that negative interest rates can be useful when it is the objective of the central bank to keep nominal rates as low as possible. Rognlie (2016) shows in a New Keynesian framework that it is sometimes optimal to set rates below zero to spur demand, and that the option of doing so lowers the optimal long-run inflation target for the central bank.

Outline. The rest of the paper is organized as follows. In Section 2, the model is explained, and in Section 3, the steady-state equilibrium is defined. Section 4 discusses the welfare properties of the model and the comparative statics of inflation and the bonds-to-money ratio. In Section 5 , I analyze the effects of monetary policy on real outcomes in the various equilibrium regimes. Finally, Section 6 concludes.

\section{The model}

Time is discrete and continues forever. There is a unit measure each of buyers and sellers in the economy, collectively called agents. There is also a unit measure of banks, and a unit measure of entrepreneurs in the economy, as well as a monetary and a fiscal authority. Each period is divided into two subperiods, called the decentralized market (DM) and the centralized market (CM). At the beginning of a period, the DM takes place, and after it closes, the CM opens and remains open until the period ends. Each seller is able to produce a special good $q$ in the DM, and each buyer is able to produce a general good $x$ in the CM. Buyers gain utility from consuming the special good in the DM and sellers gain utility from consuming the general good in the CM. In the DM, buyers and sellers are matched bilaterally at random. With probability $\sigma$, the special good $q$ produced by the seller in a match gives utility to the buyer. In the CM, there exists a centralized market for general goods. Neither general goods nor special goods can be stored by agents. The preferences of buyers are given by

$$
\mathbb{E}_{0} \sum_{t=0}^{\infty} \beta^{t}\left(u\left(q_{t}\right)-y_{t}\right)
$$

Equation (1) states that buyers discount future periods by a factor $\beta \in(0,1)$, gain utility $u(q)$ from consuming the special good in the DM, with $u(0)=0, u^{\prime}(q)>0, u^{\prime \prime}(q)<0, u^{\prime}(0)=\infty$, and 
linear disutility $y$ from producing the general good in the CM. The preferences of the sellers are

$$
\mathbb{E}_{0} \sum_{t=0}^{\infty} \beta^{t}\left(-c\left(q_{t}\right)+x_{t}\right)
$$

Sellers also discount future periods by a factor $\beta$, gain disutility $c(q)$ from producing in the DM and linear utility $x$ from consuming in the $\mathrm{CM}$, with $c(0)=0, c^{\prime}(0)=0, c^{\prime}(q)>0, c^{\prime \prime}(q)>0$, and $c(\bar{q})=u(\bar{q})$ for some $\bar{q}>0$. Furthermore, I define $q^{*}$ as $u^{\prime}\left(q^{*}\right)=c^{\prime}\left(q^{*}\right)$; i.e., the socially efficient quantity.

In the DM, buyers are randomly allocated to two different kinds of meetings, namely an outside or an inside meeting. In an outside meeting, sellers accept only fiat (outside) money to settle a transaction, whereas in an inside meeting, other liquid assets are also eligible, especially bank deposits (inside money). The kind of meeting buyers are having in the next DM is already revealed in the $\mathrm{CM}$ of the previous period. This can be imagined as buyers knowing what kind of good they want to purchase in the next period, and whether the seller of that good accepts debit cards and checks, or only cash. In any given DM, the fraction of buyers who have an inside meeting is $\eta$, while the remaining fraction $1-\eta$ have an outside meeting and therefore need cash to settle transactions in the DM. These fractions remain constant over time, but individual buyers will switch from one type of meeting to the other from period to period at random. It can be assumed that a fraction $\eta$ of sellers own the technology that is required to use debit cards, while it would be infinitely costly for the remaining $1-\eta$ sellers to acquire this technology. None of the sellers are willing to accept bonds or claims on capital as a means of payment during the DM, as sellers are not able to verify the validity of these assets.

Banks and entrepreneurs are agents that exist from the beginning of the $\mathrm{CM}$ of period $t$ until the end of the CM of period $t+1$, while a new set of banks and entrepreneurs emerge at the beginning of the $\mathrm{CM}$ in period $t+1$, such that there are always two sets of each of them during the $\mathrm{CM}$ of each period, but only one set of them during the DM, making their lifespans similar to lifespans of agents in overlapping generations models. Banks and entrepreneurs cannot produce any goods and gain utility from consumption during their second $\mathrm{CM}$ only ${ }^{4}$. Banks are not anonymous in the $\mathrm{CM}$ and are under full commitment, so that they will always pay back their debt. Because of

\footnotetext{
${ }^{4}$ These assumptions about banks and entrepreneurs greatly simplify the analysis without qualitatively changing the results. If banks were infinitely lived and could consume in every CM, they could retain some deposits for the purpose of immediate consumption, and consequently there would be more endogenous variables to keep track of. Similarly, entrepreneurs could start building up their own capital and would therefore need different amounts of credit.
} 
these features, sellers who have the respective technology are willing to accept a claim to an asset that the bank holds (an IOU, or, more precisely, a bank deposit) as a means of payment, knowing that it will allow them to obtain the asset from the bank in the following CM. Banks take prices as given and compete for deposits.

In the CM of each period, each entrepreneur has access to an individual investment opportunity that yields $f(k)$ during the next CM, with $f^{\prime}(k)>0, f^{\prime \prime}(k)<0$, and $f^{\prime}(0)=\infty$. During the CM, general goods $x$ can be transformed into capital $k$ one for one, so entrepreneurs need to acquire general goods in order to invest. Because entrepreneurs have no funds of their own, they need external funding. An entrepreneur can choose to be matched with either a buyer or a bank - but in equilibrium, he will always choose to be matched with a bank ${ }^{5}$. Once the match is formed, banks can make take-it-or-leave-it offers to entrepreneurs ${ }^{6}$. Due to limited commitment, entrepreneurs can only pledge to pay back $\chi f(k)$, with $\chi \in(0,1]$. The parameter $\chi$ can be interpreted as a financial friction ${ }^{7}$.

The socially efficient quantity of capital $k^{*}$ is given by $f^{\prime}\left(k^{*}\right)=1 / \beta$. Because of the concavity of $f(k)$ and the market structure of the banking market, banks can make profits by investing in capital (i.e., lending to entrepreneurs), which in turn creates the banks' demand for deposits, because they do not have any funds of their own to invest. Buyers facing an inside meeting in the DM are willing to supply these deposits as long as these earn a return that is at least as high as fiat money, because they know that they can use them as a means of payment. Deposits are nominal claims and are denoted by $d$. The interest paid on deposits is called $i^{d}$, and it is paid out in the CM. To satisfy the demand for deposits, banks can also invest in fiat money or government bonds. Banks are essential in this model because they are able to perform a liquidity transformation they issue liquid assets (deposits) by investing in illiquid assets (bonds and capital).

The monetary authority issues fiat money $M_{t}$, which it can produce without cost. If fiat money

\footnotetext{
${ }^{5}$ Because banks can create liquid assets, it is cheaper for them to lend to entrepreneurs than it would be for buyers. Therefore, the offer an entrepreneur gets from a bank always weakly dominates the offer he would get from a buyer.

${ }^{6}$ One rationale for the one to one matching between entrepreneurs and banks is that banks have a regional monopoly in issuing loans, or a monopoly in issuing loans to a specific sector of the economy. Both of these monopolies could arise due to lower monitoring costs compared to other banks.

${ }^{7}$ Along the lines of Kehoe and Levine (1993), $\chi$ could be made endogenous by assuming that entrepreneurs live forever, but get excluded from receiving credit in the future if they don't pay back. $\chi$ then has to be set such that the discounted future profits of acting as an entrepreneur are higher than the immediate profits of consuming the full payoff of the investment opportunity.
} 
is held by a bank, it can be considered reserves, but reserves and fiat money are the same object in this model. The monetary authority always implements its policies at the beginning of the CM. The amount of general goods that one unit of fiat money can buy in the CM of period $t$ is denoted by $\phi_{t}$, the inflation rate is defined as $\phi_{t} / \phi_{t+1}-1=\pi_{t+1}$, and the growth rate of fiat money from period $t-1$ to $t$ is $\frac{M_{t}}{M_{t-1}}=\gamma_{t}^{M}$. I will assume $\pi_{t} \geq 0 \forall t$ throughout the paper, unless stated differently. The monetary authority issues fiat money either by trading in the CM or by issuing lump-sum transfers to agents. To issue the amount $M_{t}-M_{t-1}$ of newly created fiat money by trading, the monetary authority buys bonds with the corresponding value $\phi_{t}\left(M_{t}-M_{t-1}\right)$ from either agents, banks, or directly from the fiscal authority. Equally, to withdraw fiat money, the monetary authority sells bonds to banks in exchange for fiat money. Such trades are called openmarket operations. The bonds held by the central bank are denoted by $b_{t}^{M}$. The balance sheet of the monetary authority consists of bonds on the assets side and fiat money on the liabilities side. Note that the monetary authority will make profit if it uses open-market operations and a positive interest rate is paid on bonds. This central bank profit (in real terms) is given by $\Pi_{t}=\phi_{t} i^{B} b_{t-1}^{M}$, where $i^{B}$ denotes the interest rate on bonds. This profit is transferred to the fiscal authority.

The fiscal authority is the only entity in the model which is able to levy taxes. It has to finance some spending $g_{t}$ in each period, and can do so by levying lump-sum taxes $\tau$, issuing bonds $B$, or using the profits earned by the monetary authority. This gives rise to the following government budget constraint:

$$
\phi_{t} B_{t}+2 \tau_{t}+\Pi_{t}=\phi_{t}\left(1+i^{B}\right) B_{t-1}+g_{t} .
$$

It is assumed that the government determines exogenously how to finance its expenditure, and that it always finances some fraction of its expenditure through bonds. This implies that the quantity of bonds in the economy is positive, and that the fiscal authority has to pay the interest rate $i^{B}$ which clears the bond market. The growth rate of bonds is defined as $\frac{B_{t}}{B_{t-1}}=\gamma_{t}^{B}$.

Next, I look at the banks' problem to determine the demand for deposits. After that, I solve the buyer's problem to determine the supply of deposits, and then turn to the equilibrium analysis in the next section.

\subsection{The banks' problem}

A bank has to decide on the value of deposits that it wishes to attract and how to invest these funds in the different asset classes. Its goal is to maximize consumption in the following period, 
which translates into maximizing the difference between the value of its assets and its liabilities in period $t+1$. This can be summed up in the following maximization problem ${ }^{8}$ :

$$
\begin{gathered}
\max _{d_{t}, \alpha_{M}, \alpha_{B}} \chi f\left(\left(1-\alpha_{M}-\alpha_{B}\right) \phi_{t} \eta d_{t}\right)+\alpha_{B} \phi_{t+1}\left(1+i^{B}\right) \eta d_{t}+\alpha_{M} \phi_{t+1} \eta d_{t}-\phi_{t+1}\left(1+i^{d}\right) \eta d_{t} \\
\text { s.t. } \quad \alpha_{M} \geq 0 \\
\alpha_{B} \geq 0 \\
\alpha_{B}+\alpha_{M} \leq 1 .
\end{gathered}
$$

The first term represents the value of lending to entrepreneurs; the second term represents the real value of the bonds held by the bank, with $\alpha_{B}$ being the share of assets invested in bonds; the third term represents the real value of the fiat money held as reserves, with $\alpha_{M}$ being the share of assets invested in fiat money; and the final term represents the real value of the deposits. The constraints ensure that investment in all types of assets is non-negative. Note that the last constraint never binds due to the assumption that $f^{\prime}(0)=\infty$. The maximization problem leads to the following first-order conditions:

$$
\begin{gathered}
\chi f^{\prime}\left(\left(1-\alpha_{M}-\alpha_{B}\right) \phi_{t} \eta d_{t}\right) \geq \frac{1}{1+\pi_{t+1}} \\
\chi f^{\prime}\left(\left(1-\alpha_{M}-\alpha_{B}\right) \phi_{t} \eta d_{t}\right) \geq \frac{1+i^{B}}{1+\pi_{t+1}} \\
\left(1-\alpha_{M}-\alpha_{B}\right) \chi f^{\prime}\left(\left(1-\alpha_{M}-\alpha_{B}\right) \phi_{t} \eta d_{t}\right)+\alpha_{B} \frac{1+i^{B}}{1+\pi_{t+1}}+\alpha_{M} \frac{1}{1+\pi_{t+1}}=\frac{1+i^{d}}{1+\pi_{t+1}} .
\end{gathered}
$$

The conditions (4) and (5) show that banks should invest in such a way that the real return on bonds and fiat money equals the return on capital. If the constraints are binding, the firstorder conditions (4) and (5) will not hold with equality, meaning that banks will not invest in fiat money and bonds, respectively. This ensures that the marginal return on all assets with positive investment shares is equal in equilibrium.

Condition (6) shows that banks should demand the amount of deposits that allows them to equalize the marginal return on their assets to the marginal cost of deposits for given investment shares and interest rates. Equation (6) also shows that the banks' demand schedule for deposits is decreasing in the interest rate paid on deposits $i^{d}$.

\footnotetext{
${ }^{8} \mathrm{I}$ assume for now that all entrepreneurs choose to be matched with a bank, and thus all banks have a match and can lend to an entrepreneur. I will later show that this is true in equilibrium.
} 


\subsection{The buyers' problem}

The buyer's problem is in general very similar to Lagos and Wright (2005) and Rocheteau and Wright (2005), with the exception that buyers in inside meetings have a choice between deposits and fiat money. This means that for a buyer in an inside meeting, his liquid assets, i.e., the nominal amount that he can use in a DM meeting, are equal to $\left(1+i^{d}\right) d+m$, while for a buyer in an outside meeting, this amount is simply $m$.

In the DM, it is assumed that buyers can make a take-it-or-leave-it offer ${ }^{9}$. The optimal choice of liquid assets transferred to the seller for buyers in inside meetings $l^{i}$ is given by:

$$
l^{i}=\left\{\begin{array}{lll}
\frac{c\left(q^{*}\right)}{\phi_{t}} & \text { if } \quad\left(1+i^{d}\right) \phi_{t} d+\phi_{t} m \geq c\left(q^{*}\right) \\
\left(1+i^{d}\right) d+m & \text { if } \quad\left(1+i^{d}\right) \phi_{t} d+\phi_{t} m<c\left(q^{*}\right) .
\end{array}\right.
$$

So buyers will spend the amount that allows them to buy the socially efficient quantity if they can, or all they have otherwise.

The optimal portfolio choice of buyers in inside meetings is then given by:

$$
\begin{aligned}
\Rightarrow & \max _{d \geq 0, m \geq 0, b \geq 0}\left[-\left(\frac{1+\pi_{t+1}}{\beta}-\left(1+i^{d}\right)\right) \phi_{t+1} d-\left(\frac{1+\pi_{t+1}}{\beta}-1\right) \phi_{t+1} m\right. \\
& \left.-\left(\frac{1+\pi_{t+1}}{\beta}-\left(1+i^{B}\right)\right) \phi_{t+1} b+\sigma \max _{l^{i} \leq\left(1+i^{d}\right) d+m}\left\{u \circ c^{-1}\left(\phi_{t+1} l^{i}\right)-\phi_{t+1} l^{i}\right\}\right] .
\end{aligned}
$$

In (8), the first three terms denote the cost of holding deposits, fiat money, and bonds, respectively. The final term is the surplus from the DM; i.e., the benefit of holding more liquid assets. Since bonds are not a liquid asset in this economy, agents are only willing to hold them if $\frac{1+\pi_{t+1}}{\beta} \leq\left(1+i^{B}\right)$. For the liquid assets, it is clear that deposits always strictly dominate fiat money as long as the interest rate on deposits is positive, and weakly dominate fiat money if the interest rate on deposits is zero. Buyers in inside meetings will therefore hold no fiat money if $i^{d}>0$, and I assume without loss of generality that they also hold no fiat money at $i^{d}=0$. If the interest rate on deposits is negative, however, no buyers are willing to hold deposits, because they can switch to fiat money instead. This creates a zero lower bound for the interest rate on deposits. Since the cost of holding deposits is decreasing in the interest rate on deposits, the supply of deposits provided by buyers is upward-sloping in the interest rate on deposits.

\footnotetext{
${ }^{9}$ The effect of different bargaining protocols and powers has been analyzed by Lagos and Wright (2005), and the effect of different market structures in the DM has been analyzed by Rocheteau and Wright (2005). Their findings apply here as well.
} 
Now we turn to the portfolio choice of buyers preparing for outside meetings. These buyers' optimal choice in the DM is:

$$
l^{o}=\left\{\begin{array}{lll}
\frac{c\left(q^{*}\right)}{\phi_{t}} & \text { if } & \phi_{t} m \geq c\left(q^{*}\right) \\
m & \text { if } & \phi_{t} m<c\left(q^{*}\right) .
\end{array}\right.
$$

This is similar to equation (7), except that fiat money is the only liquid asset for these buyers. The optimal portfolio choice of buyers in outside meetings is given by:

$$
\begin{aligned}
\Rightarrow \max _{d \geq 0, m \geq 0, b \geq 0}[ & -\left(\frac{1+\pi_{t+1}}{\beta}-\left(1+i^{d}\right)\right) \phi_{t+1} d-\left(\frac{1+\pi_{t+1}}{\beta}-1\right) \phi_{t+1} m \\
& \left.-\left(\frac{1+\pi_{t+1}}{\beta}-\left(1+i^{B}\right)\right) \phi_{t+1} b+\sigma \max _{l^{\circ} \leq m}\left\{u \circ c^{-1}\left(\phi_{t+1} l^{o}\right)-\phi_{t+1} l^{o}\right\}\right] .
\end{aligned}
$$

This is the same as in equation (8), but with a different constraint for the inner maximization problem. Buyers in outside meetings can only use fiat money in transactions, so they face a tradeoff regarding how much fiat money to hold, but there is no trade-off associated with the deposits and bonds that they hold. Therefore, bonds and deposits will only be held by these buyers if it is costless or even beneficial for them to hold these assets. In what follows, I will denote the quantities traded in inside meetings as $q^{i}$ and in outside meetings as $q^{o}$.

If a buyer were to be matched with an entrepreneur, he would be willing to lend to the entrepreneur such that $\chi f(k)=\frac{1}{\beta}$. In the next section, I will show that banks are willing to lend at least this amount to entrepreneurs, which shows that entrepreneurs always weakly prefer to borrow from banks. Thus, all entrepreneurs choose to be matched with a bank.

\section{Equilibrium}

The previous section established the first-order conditions resulting from the banks' and the buyers' problem. In this section, I want to analyze market clearing of bonds, fiat money, and deposits, before defining the steady-state equilibrium of the model.

\subsection{Bond market clearing}

From the government's budget constraint (equation (3)), we know that there is some amount of bonds $B_{t}$ in the economy. From the buyer's maximization problems (equations (8) and (10)), we know that buyers will only hold bonds if there is no cost to hold them. The same is true for sellers. This means that agents only hold bonds if $1+i^{B} \geq \frac{1+\pi_{t+1}}{\beta}$. However, if $1+i^{B}>\frac{1+\pi_{t+1}}{\beta}$, agents 
want to hold an infinite amount of bonds. Since the supply of bonds is finite, the interest rate on bonds will be driven down until $1+i^{B}=\frac{1+\pi_{t+1}}{\beta}$. Following Geromichalos and Herrenbrueck (2017), I will refer to this interest rate as the Fisher interest rate ${ }^{10}$. This creates an upper bound on the interest rate on bonds. The amount of bonds held by an individual agent is called $b_{t}$, so the total amound of bonds demanded by agents is $2 b_{t}$.

Since holding bonds allows banks to issue more deposits at a given interest rate, it is possible that they are willing to hold bonds even if the rate of return is lower than the Fisher interest rate. However if that is the case, all bonds have to be held by banks, because as we saw, agents are not willing to hold bonds if they pay an interest rate that does not fully compensate them for inflation and discounting. The banks' nominal demand for bonds is denoted by $\alpha_{B} \eta d_{t}$, and it is determined by equation (5). This allows us to state the market clearing condition for bonds:

$$
\begin{aligned}
\alpha_{B} \eta d_{t}+2 b_{t} & =B_{t}-b_{t}^{M} \\
\text { with } b_{t} & =0 \quad \text { if } 1+i^{B}<\frac{1+\pi_{t+1}}{\beta}, \text { and } 2 b_{t}=B_{t}-b_{t}^{M}-\alpha_{B} \eta d_{t}, \text { otherwise. }
\end{aligned}
$$

Since $b_{t}^{M}$ denotes the bond holdings of the monetary authority, $B_{t}-b_{t}^{M}$ is the supply of bonds that are publicly available, and this supply has to be equal to the private demand for bonds (demand from banks and agents). The bonds held by agents $2 b_{t}$ can take any non-negative value if bonds pay the Fisher interest rate, so if the demand of banks for bonds at the Fisher interest rate is less than the supply of bonds, $2 b_{t}$ will be equal to the difference between the supply of bonds and the banks' demand for bonds. If the interest rate on bonds is lower than the Fisher interest rate, the banks' demand for bonds must equal the supply of bonds. Since the banks' demand for bonds is downward sloping with respect to the interest rate $i^{B}$, the interest rate will decrease if the demand for bonds is higher than the supply of bonds at a specific interest rate. If the monetary authority does not make use of helicopter money, it will have to hold the same value of bonds as it has in fiat money outstanding, so that $b_{t}^{M}=M_{t}$. I will assume this for the rest of the paper, unless stated differently.

Figure 1 shows the marginal return on capital and illustrates the two quantities $\hat{k}$ and $\bar{k}$. $\hat{k}$ is the quantity that, if invested in capital, pays the same real return as the Fisher interest rate, while $\bar{k}$ is the quantity that pays the same real return as fiat money. Note that $\hat{k}=k^{*}$ for $\chi=1$. With $\chi<1, \hat{k}<k^{*}$ for sure, but $\bar{k}$ can be below or above $k^{*}$ depending on parameters. With the help

\footnotetext{
${ }^{10}$ By defining $1+r=\frac{1}{\beta}$ as the natural real interest rate, the Fisher interest rate is the nominal interest rate at which the Fisher equation (Fisher, 1930) holds for the natural real interest rate.
} 




Figure 1: Marginal return on capital.

of the quantities $\hat{k}$ and $\bar{k}$, I can now define the different cases for the interest rate on bonds, which also affect the other investment decisions of the banks. These different cases can also be seen in Figure 2, which shows the total real returns on the different assets that are available to banks in the first panel, and the investment by asset type in the second panel, both as a function of the amount of deposits a bank attracts.

Case $1 \hat{k} \geq \eta \phi_{t} d_{t}$ : In this case, the banks' investment demand can be fully satisfied by capital. Therefore, banks do not hold any bonds, and bonds pay the Fisher interest rate $1+i^{B}=\frac{1+\pi_{t+1}}{\beta}$. Case $2 \hat{k}<\eta \phi_{t} d_{t}<\hat{k}+\phi_{t}\left(B_{t}-b_{t}^{M}\right)$ : In this case, the banks' investment demand is larger than the quantity $\hat{k}$. Thus, banks also hold some bonds. However, their investment demand is still less than $\hat{k}$ plus the real value of all publicly available bonds, so some bonds are still held by agents and bonds still pay the Fisher interest rate.

Case $3 \hat{k}+\phi_{t}\left(B_{t}-b_{t}^{M}\right)<\eta \phi_{t} d_{t}<\bar{k}+\phi_{t}\left(B_{t}-b_{t}^{M}\right)$ : If this situation holds, the banks' investment demand is not satisfied even when they invest $k^{*}$ and hold all the publicly available bonds. However, the banks' investment demand is less than the sum of investment amount $\bar{k}$ and the real value of all publicly available bonds. This means that at the Fisher interest rate, the demand for bonds is higher than the supply, which in turn means that the price has to adjust for the bond market to clear, so $i^{B}$ decreases. As a result, banks can invest more in capital, because investments with lower return now also become attractive.

Case $4 \bar{k}+\phi_{t}\left(B_{t}-b_{t}^{M}\right)<\eta \phi_{t} d_{t}$ : As explained above, if $i^{B}$ falls, banks will invest more in capital. This process will continue until the amount invested reaches $\bar{k}$. If the banks' demand for investment 
marginal return

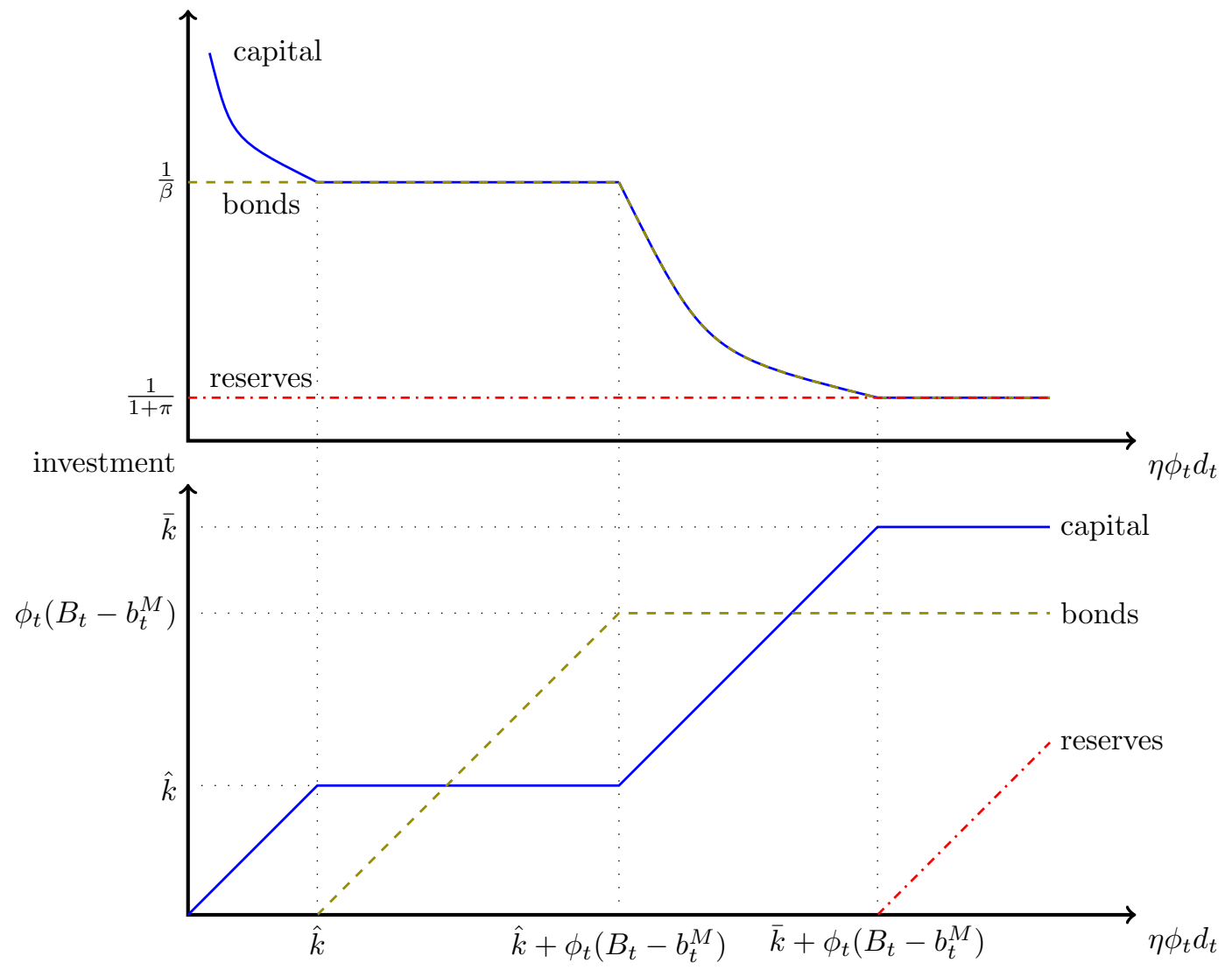

Figure 2: The first panel shows the real return on the three different assets as a function of total investment, which equals deposits received. The second panel shows the amounts invested in the separate assets as a function of total investment.

cannot be satisfied even by the real value of all publicly available bonds and $\bar{k}$, the interest rate on bonds will be driven all the way down to zero, so that bonds and fiat money become perfect substitutes. Therefore, although at $i^{B}=0$ the banks' demand for bonds is still higher than the supply of bonds, the interest rate will not decrease further, and instead the banks will hold reserves.

\subsection{Money market clearing}

Next, we can state the market clearing condition for fiat money:

$$
(1-\eta) z^{m}+\alpha_{M} \eta z^{d}=\phi_{t} M_{t}
$$

Here, $z^{m}=\phi_{t} m_{t}$ and $z^{d}=\phi_{t} d_{t}$, so the left-hand side denotes the total real demand for fiat money, given by real balances of buyers in monetary meetings, and the real money holdings 
of banks. This demand has to equal the supply of fiat money. $z^{m}$ results from (10). For any $\pi_{t+1}>\beta-1$, buyers in outside meetings spend all their money holdings, so the first-order condition of (10) can be written as:

$$
\frac{u^{\prime} \circ c^{-1}\left(\phi_{t+1} m_{t}\right)}{c^{\prime} \circ c^{-1}\left(\phi_{t+1} m_{t}\right)}=1+\frac{1}{\sigma} \cdot \frac{1+\pi_{t+1}-\beta}{\beta} .
$$

This shows that the real amount of buyers' money holdings negatively depends on inflation. $z^{d}$ is the real value of the equilibrium-level of deposits, which is given by the level of deposits at market clearing. If $\alpha_{M}$ is positive, $z^{d}$ is also decreasing with regard to inflation.

\subsection{Deposits market clearing}

The analysis of bond market clearing showed that there are four different cases regarding the banks' investment in bonds. It turns out that this also leads to the existence of four different cases for deposit market clearing, which I will explain in this section.

Deposit market clearing is given by the deposit interest rate for which the demand of deposits from banks equals the supply of deposits from buyers. From equation (6), we know that the marginal return of a banks' investment is equal to the deposit interest rate in equilibrium. In the upper panel of figure 2, the upper frontier gives the marginal return of a banks' assets for a given amount of deposits. Thus, we can interpret this as a banks' demand schedule of deposits for a given interest rate. Since this demand schedule is non-monotone and has four sections, the properties of the deposit market equilibrium differ across these four sections.

The buyers' problem (8) is also non-monotonic, so we have to distinguish between three cases, which depend on the cost of holding deposits:

Case a $1+i^{d}=\frac{1+\pi_{t+1}}{\beta}$ : In this case, buyers are completely compensated for inflation and discounting by the interest rate, so that the interest rate on deposits is equal to the Fisher interest rate. In this situation, the supply of deposits is any value larger or equal to the value of deposits needed to pay for $q^{*}$ in the DM, which is $d_{t}^{*}=\frac{c\left(q^{*}\right)}{\left(1+i^{d}\right) \phi_{t}}$. So to determine whether $1+i^{d}=\frac{1+\pi_{t+1}}{\beta}$ constitutes an equilibrium, we have to check whether the banks' demand for deposits at the Fisher interest rate is at least $d^{*}$. From the bond market clearing, we know that this is only possible in the cases 1 and 2 , so case a can only occur if

$$
\hat{k}+\phi_{t}\left(B_{t}-b_{t}^{M}\right) \geq \eta \phi_{t} d_{t}^{*}=\eta c\left(q^{*}\right) \frac{\beta}{1+\pi_{t+1}},
$$


i.e., if the amount of deposits needed to acquire first-best consumption in the DM is less than all assets that pay a marginal return of $\frac{1}{\beta}$, which is capital $\hat{k}$ plus all publicly available bonds. If condition (14) holds, the efficient quantity $q^{*}$ is traded in the DM, the equilibrium-level of deposits equals the demand for deposits given by equation (6), and the equilibrium interest rate on deposits is $i^{d}=\frac{1+\pi_{t+1}}{\beta}-1$.

Case $\mathbf{b} 1+i^{d}<\frac{1+\pi_{t+1}}{\beta}$ : From the considerations above, we know that this can constitute an equilibrium only if (14) does not hold. In this case, deposits are costly to hold, which means that buyers will not hold a higher value of deposits than they want to spend in the DM, so $l^{i}=\left(1+i^{d}\right) d$. Then, the solution to the maximization problem in (8) becomes:

$$
\frac{u^{\prime} \circ c^{-1}\left(\phi_{t+1}\left(1+i^{d}\right) d\right)}{c^{\prime} \circ c^{-1}\left(\phi_{t+1}\left(1+i^{d}\right) d\right)}=1+\frac{1}{\sigma} \cdot \frac{1+\pi_{t+1}-\beta\left(1+i^{d}\right)}{\beta\left(1+i^{d}\right)} .
$$

Case $\mathbf{c} 1+i^{d}>\frac{1+\pi_{t+1}}{\beta}$ : In this situation, the cost of holding deposits is negative, so buyers want to supply an infinite amount of deposits. However, since demand for deposits is well-defined for any $i^{d}$ and decreasing with regard to the interest rate, we can conclude that in this case the supply of deposits is higher than demand, which will drive down the interest rate. Therefore, this case cannot be an equilibrium.

So to sum up, the deposit demand side gives rise to four cases that are potentially part of an equilibrium as explained in Section 3.1, while the deposit supply side gives rise to two cases that are potentially part of an equilibrium as explained above. However, because case a from the supply side can only occur simultaneously with cases 1 or 2 from the demand side, and case b can only occur with cases 3 and 4 , the four equilibrium cases are fully characterized by the four cases from the demand side, so I will refer to them as equilibrium cases 1-4 from now on.

Figure 3 shows the demand and supply curves for deposits. The four graphs depict the four different equilibrium cases. The banks' demand curve for deposits consists of four segments, which correspond to the four cases that are prevalent on the bond market: the upper decreasing segment (case 1), the upper flat segment (case 2), the lower decreasing segment (case 3), and the lower flat segment (case 4). As explained above, the banks' demand for deposits is decreasing with respect to the interest rate on deposits when an increase in deposits leads to a decrease in their marginal return, which happens in cases 1 and 3 . In cases 2 and 4, banks can react to an increase in deposits by holding more bonds (case 2) or more fiat money (case 4), which leaves their marginal return unchanged, so that their demand for deposits is not decreasing with regard to $i^{d}$ in these regions. 


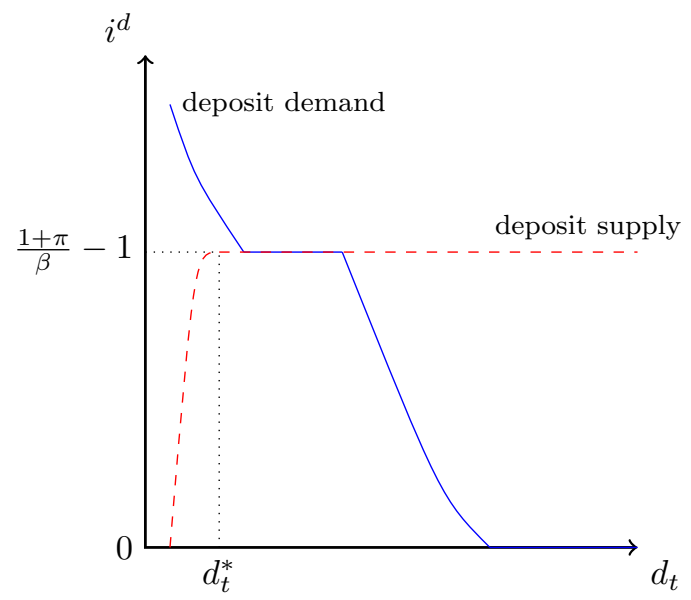

(a) Equilibrium case 1 .



(c) Equilibrium case 3.

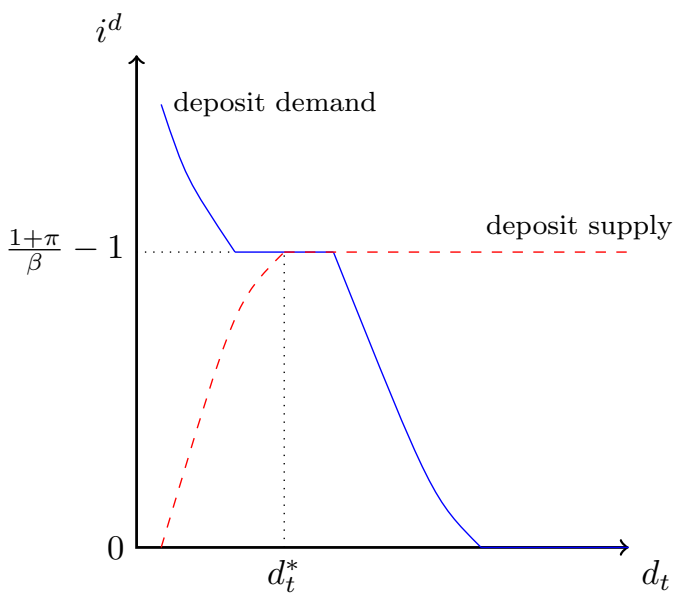

(b) Equilibrium case 2.



(d) Equilibrium case 4.

Figure 3: The four equilibrium cases.

The cases a and b resulting from the buyers' problem are reflected by the flat segment (case a) and the increasing segment (case b) of the buyers' supply curve, respectively. As shown in graphs 3a and $3 \mathrm{~b}$, the flat segment of the buyers' supply curve can only intersect the upper flat segment of the banks' demand curve ${ }^{11}$. In equilibrium case 1 , buyers actually hold excess deposits (i.e., more than they need for transactions in the DM), because banks want to attract more deposits in order to be able to invest up to $\hat{k}^{12}$. In equilibrium case 2 , banks need to hold some bonds in order to satisfy the buyers' demand for deposits. In equilibrium case 3, even holding all publicly available

\footnotetext{
${ }^{11}$ This is because both flat segments occur at the Fisher interest rate.

${ }^{12}$ Note that it is impossible for an equilibrium to occur where deposits are strictly smaller than $\hat{k}$. Banks always want to invest up to $\hat{k}$, because at $\hat{k}$, the marginal return on capital equals the upper bound of the deposit interest rate. This shows that entrepreneurs would never prefer to borrow from agents instead of banks, because agents would never be willing to lend more than $\hat{k}$ to entrepreneurs (if $\chi$ is the same for agents and banks).
} 
bonds does not offer enough investment opportunities with high returns, so $d_{t}<d_{t}^{*}$ in equilibrium, the deposit interest rate does not fully compensate for inflation, and capital investment is above $\hat{k}$. Finally, in equilibrium case 4 , even investing $\bar{k}$ and holding all publicly available bonds is not enough to satisfy the buyers' demand for deposits at $i^{d}=0$, so banks also hold fiat money.

Equilibrium case 4 corresponds to the zero lower bound, which is of particular interest given the events of the financial crisis from 2007-2009. In this model, the zero lower bound is more likely to occur in the following situations: (1) when the banks' demand curve for deposits is relatively steep, i.e., when there is a sharp fall in demand for small increases in the interest rate on deposits, which happens if the return on capital is not very high; (2) when the upper flat segment in the banks' demand curve is relatively short, where its length is given by the bonds-to-money ratio, (3) if $d^{*}$ is relatively large and / or if the buyers' supply schedule for deposits is relatively steep, which happens when there are big gains from trade to be made in the DM and when buyers are not very sensitive to the cost of holding money, (4) if limited commitment issues are severe, i.e., when $\chi$ is low, and (5) when steady-state inflation is low. To sum up, the drivers increasing the likelihood of a liquidity trap occuring are the specific forms of the functions $f(k), u(q)$, and $c(q)$, the parameter $\chi$, as well as the bonds-to-money ratio and the inflation rate $\pi$. Out of these drivers, only the bonds-to-money ratio and the inflation rate are policy variables, while the others are fundamentals.

\subsection{Steady-state equilibrium}

In a steady-state equilibrium, the inflation rate is usually pinned down by the money growth rate in New Monetarist models. That is also true in this model, but because of the importance of government bonds for monetary policy, additional requirements have to be met for a steady state:

Definition 1. In a steady state, the growth rates of fiat money and bonds have to be equal and jointly define the inflation rate: $\gamma_{t}^{M}=\gamma_{t}^{B}=1+\pi_{t}$.

This relation is driven by the market clearing condition for bonds (equation (11)), as in this equation real variables can only stay constant over time if the growth rates of fiat money and bonds are equal ${ }^{13}$.

With the help of this steady state definition, we are now ready to define a steady-state equilibrium:

Definition 2. An equilibrium is a sequence of prices $i^{B}, i^{d}, \pi_{t+1}$, quantities $z_{t}^{d}, z_{t}^{m}, b_{t}, l_{t}^{i}$, and ratios $\alpha_{M}$, and $\alpha_{B}$ that simultaneously solve the equations (4), (5), (6), (7), (8), (13), (11) and satisfy

\footnotetext{
${ }^{13}$ Note that this also keeps the share of debt to total government spending constant.
} 
the corresponding complementary slackness condition on agents' bond holdings, and the condition from definition $1 \forall t$.

With the help of this definition, I can also formally define the four equilibrium cases characterized in Section 3.3. In case 1, $\alpha_{M}=0$ and $\alpha_{B}=0$, such that both (4) and (5) do not hold with equality. Further, from (11), $b_{t}>0$, such that $1+i^{B}=\frac{1+\pi_{t+1}}{\beta}$. In case 1 and 2 , from (7), $l^{i}=\frac{c(q)}{\phi_{t}}$, while in cases 3 and $4, l^{i}=\left(1+i^{d}\right) \phi_{t} d_{t}+\phi_{t} m_{t}$ and thus (8) reduces to (15). In cases 2 and 3, $\alpha_{M}=0$, but $\alpha_{B}>0$, and so (4) still does not hold with equality, but (5) does. In case 2, from (11), $b_{t}>0$, so $1+i^{B}=\frac{1+\pi_{t+1}}{\beta}$, while in case $3, b_{t}=0$, and so $\alpha_{B} \eta d_{t}=B_{t}-b_{t}^{M}$. Finally, in case 4 , also $\alpha_{M}>0$, and so (4) holds with equality too. Everything else is the same as in case 3.

\section{Comparative statics and welfare}

In this section, I want to analyze the comparative statics regarding two policy variables, namely the inflation rate $\pi_{t+1}$, and the quantity of publicly available bonds, or, more precisely, the bondsto-money ratio $\frac{B_{t}-b_{t}^{M}}{M_{t}}$. I analyze the effect they have on the quantities $k, q^{i}$, and $q^{o}$, as these are the only quantities relevant for welfare. At the end of this section, I look at the welfare properties of the different equilibrium cases.

\subsection{Changes in the bonds-to-money ratio}

While the availability of bonds does not matter for agents directly, it is relevant for banks, as a higher bonds-to-money ratio expands the universe of possible investments for them. From the equilibrium analysis, we learned that bonds are plentiful in equilibrium cases 1 and 2, but scarce in the equilibrium cases 3 and 4 . In equilibrium case 1 , banks are not investing in bonds even though they are plentiful, so the quantity of bonds available is irrelevant for real allocations in this case. In equilibrium case 2 , banks only hold some of the bonds, and the bond interest rate equals the Fisher interest rate. In this case, small changes in the bonds-to-money ratio have no effect on the real allocation as they leave the interest rate unchanged. However, a large decrease in the bonds-to-money ratio could change the equilibrium from case 2 to case 3 , or even case 4 .

In equilibrium case 3, banks hold all publicly available bonds, so changes in the bonds-to-money ratio directly affect the banks' investment decision, which in turn affects real allocations. The bond interest rate is positively related to the bonds-to-money ratio in this equilibrium case, so an increase in the bonds-to-money ratio leads to an increase of the bond interest rate. In turn, a higher bond interest rate leads to an increase in $q^{i}$ and a decrease in $k . q^{o}$ is not affected by changes in the bonds-to-money ratio. In equilibrium case 4 , the bond interest rate is equal to zero. 
Therefore, small changes in the bonds-to-money ratio have no effect on the interest rate, and thus also do not affect real allocations. However, large enough increases in the bonds-to-money ratio can get the economy into equilibrium case 3 or even case 2 .

\subsection{Changes in the steady-state inflation rate}

From equation 13, we know that $q^{o}$ only depends on the inflation rate. Away from the Friedman rule $(1+\pi=\beta), q^{o}$ is decreasing with inflation, independent of the equilibrium case the economy is in.

In equilibrium cases 1,2 , and 3 , changes in inflation translate into one for one changes of the bond and deposit interest rates, therefore keeping real returns constant. In turn, this means that changes in inflation do not affect $k$ and $q^{i}$ in these equilibrium cases $^{14}$. In equilibrium case 3 , a large enough decrease in inflation could lead to a transition into equilibrium case 4.

In equilibrium case 4 , banks invest up to $\bar{k} . \bar{k}$ is increasing with inflation, which means that an increase in inflation leads to an increase in capital investment in this equilibrium case. Because the interest rate on deposits is equal to 0 in equilibrium case 4 , the real return on deposits decreases with an increase in inflation, which leads to a reduction in $q^{i}$. Large enough increases in inflation could lead to a transition from equilibrium case 4 to case 3 .

\subsection{Welfare properties of the equilibrium cases}

The first-best allocation is defined by the quantities $q^{i}=q^{o}=q^{*}$ and $k=k^{*}$. As explained in section 4.2 , the quantity of goods traded in outside meetings $q^{o}$ only depends on the inflation rate, not on the equilibrium case. Furthermore, $q^{o}<q^{*}$ for any $1+\pi>\beta$, and it is further decreasing with increases in the inflation rate.

The quantity of goods traded in inside meetings, $q^{i}$, depends on the prevalent equilibrium case. $q^{i}=q^{*}$ in equilibrium cases 1 and 2 , while $q^{i}<q^{*}$ in equilibrium cases 3 and 4 . For a given inflation rate, $q^{i}$ is smaller in equilibrium case 4 than in equilibrium case 3.

The amount of capital invested $k$ depends on the prevalent equilibrium case and on the limited commitment parameter $\chi$. If there is full commitment $(\chi=1), k=k^{*}$ in equilibrium cases 1 and

\footnotetext{
${ }^{14}$ For equilibrium cases 1 and 2 , this is obvious, as the bond market can only clear at the Fisher interest rate. In equilibrium case 3 , this can best be understood by assuming the contradiction: If deposit interest rates would not fully compensate for the increase in inflation, buyers would demand less deposits in real terms. This would mean that banks need to invest less, but the real supply of bonds is unchanged and capital investment would actually become more attractive at lower (real) deposit interest rates. This cannot be an equilibrium, because the deposit market does not clear. A similar argument could be made for an increase in interest rates that overcompensates for the increase in inflation, thus leaving only a one for one increase as a possibility.
} 
2 , while there is overinvestment $\left(k>k^{*}\right)$ in equilibrium cases 3 and 4 , with overinvestment being more severe in equilibrium case 4 for a given inflation rate. In the presence of limited commitment $(\chi<1)$ however, $k<k^{*}$ in equilibrium cases 1 and 2. Depending on the severity of the limited commitment issues, there can be over- or underinvestment in equilibrium cases 3 and 4 . If $\bar{k}<k^{*}$, there is underinvestment in both equilibrium cases 3 and 4 . If instead $\bar{k}>k^{*}$, there is overinvestment in equilibrium case 4 , while there is some bond interest rate $\frac{1+i^{B}}{1+\pi}=\chi f^{\prime}\left(k^{*}\right)$ for which $k=k^{*}$ in equilibrium case 3. For bond interest rates higher (lower) than that, $k<k^{*}\left(k>k^{*}\right)$.

Based on the above analysis, we can conclude that equilibrium cases 1 and 2 are welfaremaximizing in the absence of limited commitment for a given inflation rate. With limited commitment present, equilibrium case 3 is better in terms of welfare than equilibrium cases 1 and 2 due to the envelope theorem. If $\bar{k}>k^{*}$, equilibrium case 3 and a relatively high bond interest rate are welfare-maximizing. If $\bar{k}<k^{*}$, either equilibrium case 3 or equilibrium case 4 is welfaremaximizing, depending on the severity of the limited commitment issues and other parameters. In particular, equilibrium case 4 is more likely to be welfare-maximizing for low inflation, high limited commitment issues (low $\chi$ ), and inelastic demand for DM consumption.

\section{$5 \quad$ Monetary policy}

In this section, I want to analyze how monetary policy can affect real allocations and improve welfare. I will focus on two policy tools: (1) Large, one-time purchases or sales of government bonds, which I will interpret as quantitative easing / tightening; (2) changes in the money growth rate. Furthermore, changes in the money growth rate can be induced by either (a) open-market operations, or (b) helicopter money. Quantitative easing affects the bonds-to-money ratio, while changes in the money growth rate potentially affect the inflation rate. At the end of this section, I will introduce interest rates on reserves, and analyze how this affects economic outcomes and the effectiveness of other monetary policy tools. I will also allow for negative interest rates on reserves. Notice that I focus on the monetary authority here, assuming that the fiscal authority runs a constant bond growth rate $\gamma^{B 15}$.

\footnotetext{
${ }^{15}$ Note that Ricardian equivalence does not hold when the interest rate on bonds is below the Fisher interest rate, which is true for equilibrium cases 3 and 4 . Therefore, it is cheaper for the fiscal authority to finance its expenditure through bond issuance than to raise taxes. In equilibrium cases 1 and 2, Ricardian equivalence holds, making the fiscal authority indifferent between raising taxes or issuing debt. This shows that issuing debt weakly dominates raising taxes from the point of view of the fiscal authority. An assumption regarding the fiscal authority that is consistent with the incentives in this model is that the fiscal authority finances all its spending through debt issuance at $t=0$ and sets $\gamma^{B}=1$, i.e., it perpetually rolls over its debt.
} 


\subsection{Quantitative easing and quantitative tightening}

In this paper, I interpret quantitative easing ${ }^{16}$ as a one-time, large increase in the bonds-to-money ratio $\frac{B_{t}-b_{t}^{M}}{M_{t}}$. Likewise, quantitative tightening is interpreted as a one-time, large decrease in the bonds-to-money ratio. The monetary authority can conduct quantitative easing (tightening) by buying government bonds with newly issued currency (selling government bonds for outstanding currency), thereby increasing (decreasing) $b_{t}^{M}$. The fiscal authority could also implement quantitative easing or tightening by changing the amount of outstanding bonds $B_{t}$, but as explained above, I am focusing on policies implemented by the monetary authority, keeping the actions of the fiscal authority constant.

In section 4.1, I explained the comparative statics of changes in the bonds-to-money ratio. Given my definition of quantitative easing, these comparative statics can be interpreted as the effects of quantitative easing or tightening. Therefore, this section showed that quantitative easing can be used to move an economy from equilibrium case 2 to equilibrium case 3 , that it can lower the interest rate on bonds and deposits in equilibrium case 3, and even move the economy into equilibrium case 4 . Likewise, quantitative tightening can be used to do the reverse: Move an economy from equilibrium case 4 into equilibrium case 3 , or from equilibrium case 3 into equilibrium case 2 , and increase the bond and deposit interest rate in equilibrium case 3. By combining these results with the findings from section 4.3 , we can conclude that quantitative easing can be welfareimproving in the presence of limited commitment issues and a high bonds-to-money ratio (i.e., when equilibrium case 4 is welfare-maximizing, but the economy is in equilibrium cases 2 or 3 initially), while quantitative tightening can be welfare-improving in the absence of limited commitment issues, and especially for a low bonds-to-money ratio (i.e., when equilibrium case 2 is welfare-maximizing, but the economy is in equilibrium case 3 or 4 initially). If it would be welfare-improving to increase investment further in equilibrium case 4, quantitative easing is ineffective.

\subsection{Changing the fiat money growth rate}

As shown in definition 1 , in the long run the growth rates of fiat money and bonds have to be equal. Since I assume that the fiscal authority commits to a constant bond growth rate, this essentially means that the steady-state inflation rate is determined by the fiscal authority. In this section, I want to analyze whether the monetary authority can temporarily change the inflation rate by

\footnotetext{
${ }^{16}$ It is important to distinguish this policy from what I call open-market operations, which is the continuous issuance of newly printed currency through bond purchases. I will make this distinction more clear in the section about open-market operations.
} 
choosing a fiat money growth rate that is different from the bond growth rate. For simplicity, I assume that the monetary authority deviates for one period, before reverting to the steady state level, but the analysis can be generalized to deviations that are longer than one period. Additionally, I assume that this deviation is announced one period prior to the implementation; i.e., if the monetary authority plans to set $\gamma_{t+1}^{M}$ above the steady state level, it will announce that it will do so in period $t$. The timing of events is important, since this policy only has real effects due to the announcement ${ }^{17}$. I will then solve for the equilibrium in which the economy returns most quickly to the steady state. Because there are typically multiple non-steady state equilibria in a monetary model, I will only prove existence, not uniqueness.

The change in the growth rate of fiat money described above can be induced by open-market operations or by helicopter money. In some of the equilibrium cases, the effectiveness differs depending on how the newly printed currency is issued. Therefore, I consider them being two separate policy tools.

\subsubsection{Open-market operations}

In this section, I assume that all newly-printed currency is issued through open-market operations; i.e., the central bank buys bonds for newly printed fiat money. This means that $M_{t}$ increases by exactly the same amount as $b_{t}^{M}$ increases, which in turn means that the amount of publicly available bonds $B_{t}-b_{t}^{M}$ decreases by the same amount. Due to the side-effect this policy has on the amount of publicly available bonds, it's effectiveness is not the same in all equilibrium cases.

Proposition 1. In equilibrium cases 1-3, open-market operations can directly affect the inflation rate in the short run, which means that an increase in $\gamma_{t}^{M}$ induced by open-market operations leads to an increase in $\pi_{t+1}$.

The proof to this proposition can be found in the Appendix. The logic behind it is straightforward, however. Because banks are not investing in reserves, their demand for fiat money does not change even if the amount of bonds available for investment changes. Thus, the additional money supply reaches the goods market and affects prices, just as in Lagos and Wright (2005).

Since open-market operations affect inflation in equilibrium cases 1-3, we can conclude that they can affect $q^{o}$ in these equilibrium cases. From section 4.2, we know that inflation does not affect $k$ and $q^{i}$ in equilibrium cases 1-3. However, open-market operations also have an effect on the bonds-to-money ratio - setting $\gamma^{M}>\gamma^{B}$ through open-market operations leads to a decrease in

\footnotetext{
${ }^{17}$ This is similar to the effects in Gu et al. (2016), or Berentsen and Waller (2011), and Berentsen and Waller (2015).
} 
the bonds-to-money ratio. Since changes in the bonds-to-money ratio have an effect on $k$ and $q^{i}$ in equilibrium case 3 , we can conclude that open-market operations can affect these variables in this equilibrium case. In equilibrium cases 1 and 2 however, the bonds-to-money ratio does not affect $k$ and $q^{i}$, so open-market operations only affect inflation and $q^{o}$ in these cases. This shows that equilibrium case 3 most closely corresponds to a "standard" environment for monetary policy, in the sense that an increase in the money growth rate induced by open-market operations has all the effects commonly associated with it: An increase in inflation, a decrease in real ${ }^{18}$ interest rates $^{19}$, and an increase in investment.

Proposition 2. In equilibrium case 4, open-market operations are unable to affect $\pi_{t+1}$. An increase in $\gamma_{t}^{M}$ induced by open-market operations only leads to changes in $\alpha_{M}$ and $\alpha_{B}$, but none of the real variables are affected, and therefore inflation also does not change.

The proof to Proposition 2 can be found in the Appendix. The intuition behind it is as follows: In equilibrium case 4, fiat money and bonds are perfect substitutes for banks, and all available bonds are held by banks. Since an open market operation by the monetary authority reduces the supply of bonds by the same amount as it increases the supply of fiat money, the total amount of these assets in the economy remains constant. Thus, the banks absorb all the newly issued money to replace the bonds bought by the central bank, and therefore the amount of money in the goods market remains unaltered, and, consequently, the newly issued fiat money has no inflationary effect.

In equilibrium case 4 , there can be situations where an increase in inflation is welfare-improving - but this is precisely the equilibrium case where open-market operations are powerless. This shows that equilibrium case 4 can be interpreted as a liquidity trap equilibrium, as the economy is at the zero-lower bound and open-market operations are ineffective.

\subsubsection{Helicopter money}

Helicopter money differs from conventional monetary policy in its effect on $b_{t}^{M}$. Instead of issuing fiat money by buying assets and thus increasing $b_{t}^{M}$, here the monetary authority simply distributes

\footnotetext{
${ }^{18}$ Whether nominal interest rates decrease or increase depends on the relative effects of the increase in inflation and the decrease in the bonds-to-money ratio.

${ }^{19}$ This makes open-market operations not neo-Fisherian in equilibrium case 3 . Neo-Fisherism is the idea that central banks have to increase interest rates in order to increase inflation. As just explained, this is not the case for open-market operations in equilibrium case 3, as open-market operations can be used to increase inflation and simultaneously decrease interest rates. However, the model is neo-Fisherian regarding changes in inflation that leave the bonds-to-money ratio unchanged, as explained in section 4.2 .
} 
the newly printed money to agents, thus leaving $b_{t}^{M}$ unchanged. This corresponds to lump-sum transfers, which are often used as the standard transmission mechanism for monetary policy in relatively simple models.

It is possible that a central bank is restricted by law from making such transfers to agents. While these lump-sum transfers are the most straightforward way to implement helicopter money in this model, there are other methods that have the same effect. What is needed in general is that the fiat money reaches the CM goods market, and that the quantity of outstanding bonds $B_{t}-b_{t}^{M}$ is unaffected. Specifically, the following methods have the same effect as a lump-sum transfer to agents: The monetary authority could buy CM goods from the agents with the newly-printed fiat money and then simply consume these goods. The monetary authority could also transfer either the newly printed fiat money or goods acquired with that fiat money to the fiscal authority. Then, if the fiscal authority either increases spending $g_{t}$ or lowers taxes $\tau_{t}$ as a reaction to this transfer from the monetary authority, the policy tool still has the same effect as a direct transfer to agents. The tool does not work, however, if the fiscal authority instead reduces its debt as a reaction to the transfer, because then helicopter money essentially becomes equivalent to an open-market operation.

Section 5.2.1 shows that open-market operations are normally a useful tool for controlling inflation, but they are powerless in equilibrium case 4. Therefore, I want to investigate whether helicopter money can be used instead in that case.

Proposition 3. In equilibrium case 4 , helicopter money is able to affect $\pi_{t+1}$. An increase in $\gamma_{t}^{M}$ induced by helicopter money affects real variables and increases inflation.

Proposition 3 states that helicopter money enables the monetary authority to control inflation in equilibrium case 4 in the short run, which makes it a useful tool for central banks if they want to increase inflation. The proof to this proposition can be found in the appendix. The intuition for this result is that with helicopter money, banks have no incentive to absorb the additional fiat money, because their investment portfolio is unaffected by this policy. Thus, the fiat money reaches the CM goods market, and since the demand for real balances stays unaffected, inflation has to increase.

This result is interesting because we know from section 4.3 that an increase in inflation can be welfare-improving in equilibrium case 4 . This is the case when $\bar{k}<k^{*}$, and the benefits from increasing investment outweigh the welfare losses from reducing quantities traded in DM meetings. In this situation, neither quantitative easing nor open-market operations can increase welfare, but 
helicopter money can do so.

\subsection{Interest rates on reserves}

In the U.S., the Federal Reserve started to pay interest on excess reserves (IOER) in 2008. In 2016, the Fed started to increase the IOER, which was constant at $0.25 \%$ before for a long time. Due to these developments, it makes sense to analyze how IOER affects the equilibrium outcomes described in section 3 , and the effectiveness of the monetary policy tools described in this section.

The introduction of interest rates on reserves affects the banks' problem. If the monetary authority pays $1+i^{R}$ on reserves held by banks, the banks' first order conditions (4) and (6) become:

$$
\begin{gathered}
f^{\prime}\left(\left(1-\alpha_{M}-\alpha_{B}\right) \phi_{t} \eta d_{t}\right) \geq \frac{1+i^{R}}{1+\pi_{t+1}}, \quad \text { and } \\
\left(1-\alpha_{M}-\alpha_{B}\right) f^{\prime}\left(\left(1-\alpha_{M}-\alpha_{B}\right) \phi_{t} \eta d_{t}\right)+\alpha_{B} \frac{1+i^{B}}{1+\pi_{t+1}}+\alpha_{M} \frac{1+i^{R}}{1+\pi_{t+1}}=\frac{1+i^{d}}{1+\pi_{t+1}} .
\end{gathered}
$$

From these first order conditions and the previous analysis in this paper, it is clear that interest on reserves has no effect if banks hold no reserves and $i^{R}$ is below the market clearing interest rate on deposits in the absence of interest on reserves. Furthermore, no equilibrium can exist if $i^{R}$ is set above the Fisher interest rate ${ }^{20}$. Thus, I will focus the analysis on cases where the monetary authority sets $i^{R}$ somewhere between $i^{d}$ in the absence of interest on reserves, and the Fisher equation.

Interest on reserves creates a lower bound on the interest rate on deposits and the return on capital. Figure 4 shows an equilibrium with a level of $i^{R}$ that affects economic outcomes. It can be seen that the introduction of interest on reserves increases the interest rates on deposits and bonds, decreases capital investment, and increases quantities traded in inside meetings in the DM. Figure 4 also shows that any equilibrium with a binding level of $i^{R}$ resembles a liquidity trap, in the sense that banks are willing to hold excess reserves. In turn, this means that open-market operations and quantitative easing become ineffective in an equilibrium with interest on reserves: When bonds and reserves are perfect substitutes, exchanging them one for one does not affect economic outcomes. This is less worrisome than an actual liquidity trap at the zero lower bound,

\footnotetext{
${ }^{20}$ In this case, the banks would demand an infinity of reserves, because agents are willing to supply an infinity of deposits at the Fisher interest rate
} 


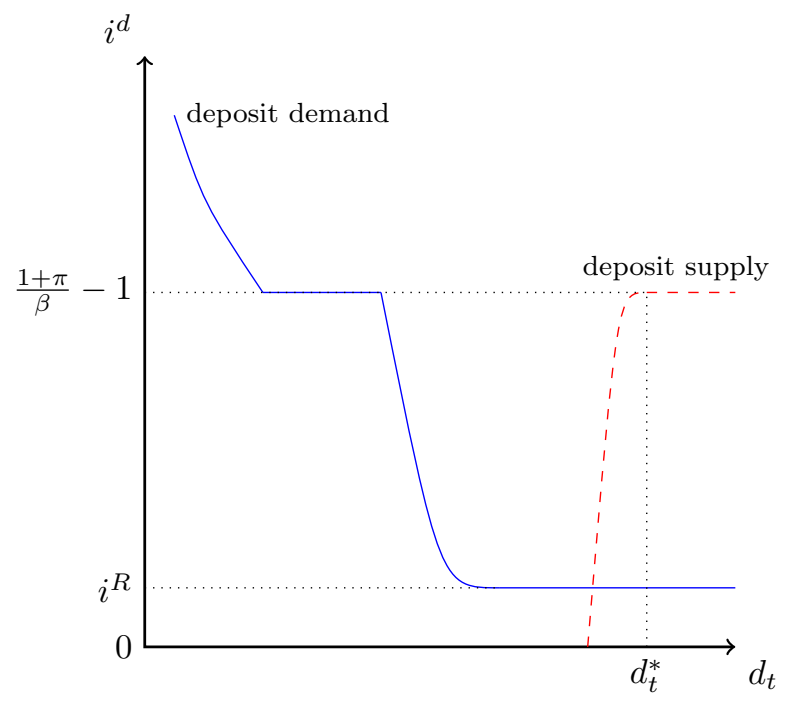

Figure 4: Deposit market clearing with interest rates on reserves.

however: With $i^{R}$, the monetary authority gains an additional tool which it can use to directly control investment and liquid asset holdings.

\subsubsection{Floor vs. channel system}

Starting in equilibrium case 4, one way for the monetary authority to target a specific $i^{d}>0$ is to set $i^{R}$ equal to its target. This policy can be interpreted as a floor system, as $i^{R}$ creates a floor for other interest rates in the economy. Instead, the monetary authority could also use quantitative tightening (i.e., reduce its balance sheet) to move the economy into equilibrium case 3 at the targeted interest rate on deposits. This policy can be interpreted as a return to the channel system, as now the monetary authority can make use of open-market operations to control the interest rate on deposits, whereas in the floor system, it can adjust the interest rate on deposits by changing $i^{R}$. In this model, there is one difference between these two systems, which can be either interpreted as an advantage or a disadvantage. As shown in section 5.2.1, open-market operations do not only affect $i^{d}$ and thus investment and liquid asset holdings, but also the inflation rate. Meanwhile, changing the interest rate on reserves does not affect the inflation rate. On the one hand, this is an advantage for the floor system, because increases in inflation decrease quantities traded in outside meetings in the DM. On the other hand, this means that the only way to affect the inflation rate in a floor system is to implement helicopter money, which has never been used so far by a central bank. Thus, a floor system allows for a cleaner implementation of monetary policy compared to a channel system, but at the cost of losing control over inflation. 


\subsubsection{Negative interest rates on reserves}

In Europe, some central banks started to charge negative interest rates on excess reserves in order to increase investment in a liquidity trap. After introducing interest on reserves, we can analyze negative interest rates on reserves by simply assuming $i^{R}<0$. It is clear that negative interest rates on reserves have no effect if banks are not holding any reserves, so I will only focus on equilibrium case 4 in this section.

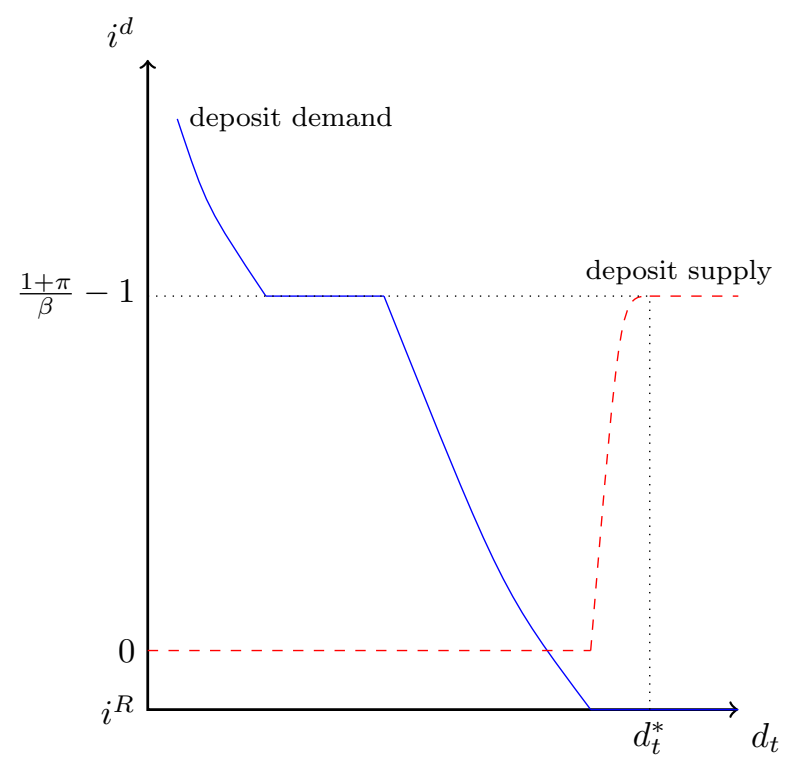

Figure 5: Deposit market clearing with negative interest rates.

Figure 5 shows how the environment for monetary policy changes when negative interest rates are introduced in an economy that originally was in equilibrium case 4 . Because fiat money dominates deposits in inside meetings if the interest rate on deposits is negative, we will never observe negative interest rates on deposits in equilibrium, which is shown by the flat segment of the deposit supply curve at zero. Therefore, banks are not performing additional investments after the introduction of negative interest rates, but get rid of their reserve holdings instead. This shows that the introduction of negative interest rates itself does not have a beneficial effect on investment, which remains constant at $\bar{k}$, or welfare. The demand for fiat money also remains unchanged after the introduction of negative interest rates on reserves. While the demand from banks decreases because they are not willing to hold reserves anymore, this decrease is offset by an increase in the demand from buyers. The demand from buyers increases because the deposits offered by banks at $i^{d}=0$ are not enough to satisfy their demand for liquid assets, and because they are indifferent between fiat money and deposits at the zero lower bound, they top up with fiat money holdings. 
For similar reasons, open-market operations are still ineffective even after the introduction of negative interest rates on reserves. Although banks are not willing to replace bonds purchased by the central bank with reserves on their balance sheets, inflation does not increase. The reason for this is that buyers in inside meetings are indifferent between deposits and fiat money at the zero lower bound, so the reduction in deposits is offset by an increase in cash holdings from buyers. Therefore, an increase in fiat money supply through open-market operations leads to an increase in demand for fiat money by the same size, thus leaving the price level unchanged. This shows that negative interest rates on reserves do not have an effect on the effectiveness of open-market operations at the zero lower bound. These results would change if negative interest rates could be implemented also on cash holdings by agents, however.

\section{Conclusion}

This paper shows that an economy can be in four different equilibrium regimes, which are defined by interest rates and the investment decisions by banks. The effects of monetary policy on real allocations differs across these equilibrium regimes. The predominant equilibrium regime is determined by real parameters and the bonds-to-money ratio. Depending on the severity of limited commitment issues between entrepreneurs and banks, each of the four equilibrium regimes can be welfare-maximizing. Policy tools can be used to transition between equilibrium cases 2, 3 and 4 and thereby increase welfare. Specifically, quantitative tightening allows to transition into equilibrium case 2 , while quantitative easing allows to transition into equilibrium case 4 , which corresponds to the zero lower bound. At the zero lower bound, an increase in inflation can be welfare improving. However, inflation cannot be affected by open-market operations at the zero lower bound. The introduction of negative interest rates on reserves cannot be used either to increase inflation or investment at the zero lower bound. Instead, helicopter money can be used.

\section{Bibliography}

Andolfatto, D. and Williamson, S. (2015). Scarcity of safe assets, inflation, and the policy trap. Journal of Monetary Economics, 73:70-92.

Bacchetta, P., Benhima, K., and Kalantzis, Y. (2016). Money and capital in a persistent liquidity trap. CEPR Discussion Paper No. DP11369.

Berentsen, A. and Waller, C. (2011). Price level targeting and stabilization policy. Journal of Money, Credit and Banking, 43(2):559-580. 
Berentsen, A. and Waller, C. (2015). Optimal stabilization policy with search externalities. Macroeconomic Dynamics, 19(3):669-700.

Boel, P. and Waller, C. J. (2019). On the theoretical efficacy of quantitative easing at the zero lower bound. FRB St. Louis Working Paper No. 2015-27.

Buiter, W. H. (2014). The simple analytics of helicopter money: Why it works - always. Economics: The Open-Access, Open-Assessment E-Journal, 8(28).

Christiano, L., Eichenbaum, M., and Rebelo, S. (2011). When is the government spending multiplier large? Journal of Political Economy, 119(1):78-121.

Cochrane, J. H. (2017). The new-Keynesian liquidity trap. Journal of Monetary Economics, 92:47-63.

Correia, I., Farhi, E., Nicolini, J. P., and Teles, P. (2013). Unconventional fiscal policy at the zero bound. American Economic Review, 103(4):1172-1211.

Dai, T. and He, C. (2018). Financial frictions, liquidity traps, and monetary policy. mimeo.

Demiralp, S., Eisenschmidt, J., and Vlassopoulos, T. (2017). Negative interest rates, excess liquidity and bank business model: Banks' reaction to uncoventional monetary policy in the euro area. Koc University - Tusiad Economic Research Forum Working Paper Series.

Dong, F. and Wen, Y. (2017). Optimal monetary policy under negative interest rate. Federal Reserve Bank of St. Louis Working Paper 2017-019A.

Eggertsson, G. B. and Krugman, P. R. (2012). Debt, deleveraging, and the liquidity trap: A Fisher-Minsky-Koo approach. The Quarterly Journal of Economics, 127(3):1469-1513.

Eggertsson, G. B. and Woodford, M. (2003). The zero bound on interest rates and optimal monetary policy. Brookings Papers on Economic Activity, pages 139-233.

Eggertsson, G. B. and Woodford, M. (2004). Policy options in a liquidity trap. American Economic Review, 94(2):76-79.

Fisher, I. (1930). The Theory of Interest. The Macmillan Company, New York.

Gali, J. (2014). The effects of a money-financed fiscal stimulus. CEPR Discussion Paper No. DP10165.

Geromichalos, A. and Herrenbrueck, L. (2017). The liquidity-augmented model of macroeconomic aggregates. Simon Fraser University, Department of Economics Working Paper 17-16. 
Gu, C., Han, H., and Wright, R. (2016). The effects of monetary policy and other announcements. mimeo.

Guerrieri, V. and Lorenzoni, G. (2017). Credit crises, precautionary savings, and the liquidity trap. The Quarterly Journal of Economics, 132(3):1427-1467.

Herrenbrueck, L. (2019). Frictional asset markets and the liquidity channel of monetary policy. Journal of Economic Theory, 181:82-120.

Kehoe, T. J. and Levine, D. K. (1993). Debt-constrained asset markets. Review of Economic Studies, 60:865-888.

Kiyotaki, N. and Moore, J. (2012). Liquidity, business cycles, and monetary policy. NBER Working Paper 17934.

Kiyotaki, N. and Wright, R. (1989). On money as a medium of exchange. Journal of Political Economy, 97 (4):927-954.

Krugman, P. R., Dominguez, K. M., and Rogoff, K. (1998). It's baaack: Japan's slump and the return of the liquidity trap. Brookings Papers on Economic Activity, 1998(2):137-205.

Lagos, R. and Rocheteau, G. (2008). Money and capital as competing media of exchange. Journal of Economic Theory, 142:247 - 258.

Lagos, R. and Wright, R. (2005). A unified framework for monetary theory and policy analysis. Journal of Political Economy, 113 (3):463-484.

Rocheteau, G. and Wright, R. (2005). Money in search equilibrium, in competitive equilibrium, and in competitive search equilibrium. Econometrica, 73(1):175-202.

Rocheteau, G., Wright, R., and Xiao, S. X. (2018). Open market operations. Journal of Monetary Economics, 98:114-128.

Rognlie, M. (2016). What lower bound? monetary policy with negative interest rates. mimeo.

Werning, I. (2012). Managing a liquidity trap: Monetary and fiscal policy. MIT mimeo.

Williamson, S. (2012). Liquidity, monetary policy, and the financial crisis: A new monetarist approach. American Economic Review, 102 (6):2570-2605.

Williamson, S. (2016). Scarce collateral, the term premium, and quantitative easing. Journal of Economic Theory, 164:136-165. 


\section{Appendix A}

\section{A.1 Proof of Proposition 1}

Consider an announcement by the monetary authority at time $t$ that $\gamma_{t+1}^{M}>\gamma^{M}$ through conventional monetary policy, where $\gamma^{M}$ is the steady state value and thus equals steady state inflation $1+\pi$. For simplicity, assume that $\pi=0$, so that $\gamma^{M}=1$, but the proof is also valid for positive inflation rates. We are trying to find an equilibrium where the economy returns to the steady state as quickly as possible, so we assume that the economy is back in the steady state in period $t+2$. Only two equilibrium conditions are directly affected by conventional monetary policy, namely the money market clearing condition (equation (12)) and the bond market clearing condition (equation (11)). However, the bond market clearing condition can only affect inflation through the demand of banks for fiat money. Since banks do not hold any fiat money in this environment, the bond market clearing condition only matters for the interest rate on deposits, but not inflation. In period $t+1$, the money market clearing condition is:

$$
\phi_{t+1} \gamma_{t+1}^{M} M_{t}=(1-\eta) z_{t+1}^{m}+\alpha_{M} \eta z_{t+1}^{d}
$$

As $\alpha_{M}=0$ in equilibrium case 1-3, we can ignore $z_{t+1}^{d}$. From equation (13), we know that $z_{t+1}^{m}$ is a decreasing function of $\pi_{t+2}$. Since we assumed that the economy returns to the steady state in $t+2, \pi_{t+2}=0$ and thus $z_{t+1}^{m}$ is also equal to its steady state value. But since $\gamma_{t+1}^{M}>1, \phi_{t+1}$ has to be lower than the previous steady-state value of money, so that $\phi_{t+1}<\phi$ is required. In period $t$, the money market clearing condition is:

$$
\phi_{t} M_{t}=(1-\eta) z_{t}^{m}+\alpha_{M} \eta z_{t}^{d}
$$

Suppose that $\phi_{t}$ is equal to its steady state value $\phi$. This requires $\pi_{t+1}>0$, since $1+\pi_{t+1}=\frac{\phi_{t}}{\phi_{t+1}}$. But since $z_{t}^{m}$ and $z_{t}^{d}$ are decreasing in $\pi_{t+1}$, they are below their steady state values, which in turn means that $\phi_{t}$ also has to be below its steady state value given the equation above, so this leads to a contradiction. Now suppose instead that $\phi_{t}=\phi_{t+1}=\phi^{\prime}$; i.e., the value of money immediately drops to the new steady-state value when the policy is announced. However, this implies $\pi_{t+1}=0$, which in turn means that $z_{t}^{m}$ and $z_{t}^{d}$ stay at their steady-state values. But given the equation above, this requires $\phi_{t}=\phi$, which also leads to contradiction. This leaves as a solution only $\phi>\phi_{t}>\phi_{t+1}$ and $\gamma_{t+1}^{M}>1+\pi_{t+1}>1$. This shows that inflation is increasing as a reaction to the increase in money growth, but not one-to-one. 


\section{A.2 Proof of Proposition 2}

Proof. Consider an announcement by the monetary authority at time $t$ that $\gamma_{t+1}^{M}>\gamma^{M}$ through conventional monetary policy, where $\gamma^{M}$ is the steady state value and thus equals steady state inflation $1+\pi$. For simplicity, assume that $\pi=0$, such that $\gamma^{M}=1$, but the proof is also valid for positive inflation rates ${ }^{21}$. For this proof, I will posit that, as a reaction to this policy, only $\alpha_{M}$ and $\alpha_{B}$ change, but the real variables do not; Then, I will show that this indeed constitutes an equilibrium.

From the money market clearing condition (equation (12)), supposing that all changes in money growth are represented in the new value $\alpha_{M}^{\prime}$, we obtain the following equation for period $t+1$ (All variables without time subscripts denote steady-state values):

$$
\begin{aligned}
\gamma_{t+1}^{M} \phi M & =(1-\eta) z^{m}+\alpha_{M}^{\prime} \eta z^{d} \\
\alpha_{M}^{\prime} & =\frac{\gamma_{t+1}^{M} \phi M-(1-\eta) z^{m}}{\eta z^{d}} .
\end{aligned}
$$

From the market clearing condition for bonds (equation (11), multiplied by $\phi$ on both sides), we obtain the following equation in period $t+1$ :

$$
\begin{aligned}
\alpha_{B}^{\prime} \eta z^{d} & =\phi\left(B-b_{t+1}^{M}\right)=\phi\left(B-\gamma_{t+1}^{M} M_{t}\right) \\
\alpha_{B}^{\prime} & =\frac{\phi\left(B-\gamma_{t+1}^{M} M\right)}{\eta z^{d}},
\end{aligned}
$$

where again I supposed that only $\alpha_{B}$ changes. The replacement of $b_{t+1}^{M}$ is possible if we assume that the monetary authority never used helicopter money in the past, but the proof also generalizes to cases where it did.

Now, adding $\alpha_{M}^{\prime}$ and $\alpha_{B}^{\prime}$ yields:

$$
\begin{aligned}
\alpha_{B}^{\prime}+\alpha_{M}^{\prime} & =\frac{\phi\left(B-\gamma_{t+1}^{M} M\right)+\gamma_{t+1}^{M} \phi_{t} M-(1-\eta) z^{m}}{\eta z^{d}} \\
& =\frac{\phi_{t} B-(1-\eta) z^{m}}{\eta z^{d}} \\
& =\alpha_{B}+\alpha_{M} .
\end{aligned}
$$

This shows that if I posit that the changes in the money growth rates are all absorbed by changes in $\alpha_{B}$ and $\alpha_{M}$, the sum of these two variables does not change. But since bonds and reserves are

\footnotetext{
${ }^{21}$ Thanks to this assumption, also nominal variables such as $M_{t}$ and $B_{t}$ have a steady state value, while for non-zero inflation, only their real counterparts $\phi_{t} M_{t}$ and $\phi_{t} B_{t}$ do. This assumption substantially simplifies the notation in this proof.
} 
perfect substitutes for banks in this equilibrium case, this implies that no real variables change. Especially, from equation (6), real investment and demand for deposits stay the same. Thus, I have shown that there is an equilibrium where only $\alpha_{B}$ and $\alpha_{M}$ change in reaction to a change in the money growth rate.

\section{A.3 Proof of Proposition 3}

Proof. I can prove this by trying to replicate the proof for proposition 2 and showing that this leads to a contradiction. Consider an announcement by the monetary authority at time $t$ that $\gamma_{t+1}^{M}>\gamma^{M}$ as a result of helicopter money, where $\gamma^{M}$ is the steady state value and thus equals steady state inflation $1+\pi$. For simplicity, assume that $\pi=0$, so $\gamma^{M}=1$, but the proof is also valid for positive inflation rates. Suppose again that in the money market clearing condition (equation (12)), only $\alpha_{M}$ changes. Since the bond market clearing condition (equation (11)) is unaffected by helicopter money, the increase in $\alpha_{M}$ is not countered by a decrease in $\alpha_{B}$, so the sum $\alpha_{M}+\alpha_{B}$ has to increase. But from equation (4), this cannot be optimal without a change in the amount of deposits, because it would drive the return on capital below the return on fiat money. Thus, the increased growth rate cannot lead to only a change in $\alpha_{M}$ and $\alpha_{B}$. But since the left-hand side of equation (12) is changing, we know that some other variables in this equation have to change too, and since all variables apart from $\alpha_{M}$ in the equation are real, it is clear that real variables have to change. To prove that inflation has to increase in this situation, we can then reason analogous to the proof of proposition 1. 